University of Nebraska - Lincoln

DigitalCommons@University of Nebraska - Lincoln

Roman L. Hruska U.S. Meat Animal Research

U.S. Department of Agriculture: Agricultural Center

Research Service, Lincoln, Nebraska

2004

Apoptosis and porcine reproductive and respiratory syndrome virus

Laura C. Miller

ARS, USDA, laura.miller@ars.usda.gov

James M. Fox

ARS, USDA, fox@email.marc.usda.gov

Follow this and additional works at: https://digitalcommons.unl.edu/hruskareports

Miller, Laura C. and Fox, James M., "Apoptosis and porcine reproductive and respiratory syndrome virus" (2004). Roman L. Hruska U.S. Meat Animal Research Center. 205.

https://digitalcommons.unl.edu/hruskareports/205

This Article is brought to you for free and open access by the U.S. Department of Agriculture: Agricultural Research Service, Lincoln, Nebraska at DigitalCommons@University of Nebraska - Lincoln. It has been accepted for inclusion in Roman L. Hruska U.S. Meat Animal Research Center by an authorized administrator of DigitalCommons@University of Nebraska - Lincoln. 


\title{
Apoptosis and porcine reproductive and respiratory syndrome virus ${ }^{\text {ts }}$
}

\author{
Laura C. Miller, James M. Fox* \\ Roman L. Hruska U.S. Meat Animal Research Center (MARC), ARS, USDA, State Spur 18D, \\ P.O. Box 166, Clay Center, NE 68933-0166, USA
}

\begin{abstract}
Despite numerous studies examining the possible induction of apoptosis in porcine reproductive and respiratory syndrome virus (PRRSV)-infected cells, it remains unclear if PRRSV infection results in direct apoptotic induction. There is clear evidence that apoptotic cells are present in tissues from PRRSV-infected pigs. However, many of these studies have failed to show that the apoptotic cells are infected with PRRSV. This has led some investigators to propose that "bystander" cells, not infected cells, become apoptotic during PRRSV infection by a yet undetermined mechanism. Studies examining the induction of the apoptotic gene expression response to PRRSV infection are needed to determine if PRRSV replication triggers an apoptotic response. We have utilized microarray and semi-quantitative reverse-transcription polymerase chain reaction (sqRT-PCR) to evaluate apoptotic gene expression in PRRSV-infected MARC-145 cells. Twenty-six apoptosis-related genes were examined during the first $24 \mathrm{~h}$ of infection and found to be unaltered, indicating that apoptotic induction was not occurring in PRRSV-infected cells. Additionally, using detection of free nucleosomal complexes, we examined cells for both apoptotic and necrotic death resulting from PRRSV infection at varying multiplicities of infection. This study indicates that PRRSV-infected MARC-145 cells undergo necrosis at a much higher level than apoptosis, and increases with virus levels used to infect the cells.
\end{abstract}

Published by Elsevier B.V.

Keywords: Apoptosis; Necrosis; PRRSV; Arterivirus

\footnotetext{
ts Mention of trade names or commercial products in this article is solely for the purpose of providing specific information and does not imply recommendation or endorsement by the U.S. Department of Agriculture.

Abbreviations: PRRSV, porcine reproductive and respiratory syndrome virus; sqRT-PCR, semi-quantitative reverse-transcription polymerase chain reaction; ATP, adenosine triphosphate; AIF, apoptosis inducing factor; FasL, Fas ligand; TRAIL, TNF-related apoptosis-inducing ligand; DISC, death-inducing signaling complex; ASFV, African swine fever virus; EAV, equine arteritis virus; CPE, cytopathic effect; TUNEL, terminal deoxynucleotidyl transferase biotin-dUTP nick end labeling; ATCC, American Type Culture Collection; CAT, chloramphenicol acetyltransferase; PKR, dsRNA-dependent protein kinase; ATF, activation transcription factor; moi, multiplicity of infection

* Corresponding author. Tel.: +1 402762 4392; fax: +1 4027624375 .

E-mail address: fox@email.marc.usda.gov (J.M. Fox).
}

0165-2427/\$ - see front matter. Published by Elsevier B.V.

doi:10.1016/j.vetimm.2004.09.004 


\section{Introduction}

Apoptosis and necrosis are two distinct processes leading to cell death, with clearly distinguishable morphological and biochemical features (Wyllie et al., 1980). However, these two processes can simultaneously occur in tissues or cells exposed to the same stimuli (Shimizu et al., 1996). Often, the intensity of the stimulus decides the prevalence of either apoptosis or necrosis (Dypbukt et al., 1994; Bonfoco et al., 1995). This suggests that while some early events may be common to both types of cell death, a downstream controller may be required to direct cells towards the organized execution of apoptosis versus the accidental death, necrosis. In this paper, we will present a brief review of apoptosis and necrosis and the relevance of each to the finding within arterivirus pathogenesis, with special reference to porcine reproductive and respiratory syndrome virus (PRRSV). We will also present data from our studies relating to apoptosis and PRRSV.

\subsection{Apoptosis}

Apoptosis, or programmed cell death, is a highly regulated process modulated by both proapoptotic and antiapoptotic cellular factors and activated by various stimuli that disturb cell metabolism and physiology (Kerr et al., 1972; Hetts, 1998). Cells exposed to proapoptotic stimuli shrink; develop blebs on their surface; undergo nuclear condensation; experience mitochondrial breakdown with the release of cytochrome $c$; and finally break into small, membranewrapped fragments. These fragments expose phosphotidylserine on the plasma membrane surface resulting in recognition and endocytosis by phagocytic cells, with secretion of anti-inflammatory cytokines. A common feature of apoptosis is cleavage of DNA into approximately $180 \mathrm{bp}$ fragments, a late event during the process that is commonly used to detect apoptotic cells.

Currently, as illustrated in Fig. 1, two distinct pathways of apoptosis have been described, intrinsic and extrinsic apoptosis (Roy and Nicholson, 2000). Intrinsic apoptosis is initiated as a response to cellular stressors such as DNA damage, toxic drugs, and unscheduled DNA replication (Roy and Nicholson, 2000). The protein p53 is activated following DNA damage and triggers apoptosis through transcriptional activation of the Bcl-2 associated (Bax) gene (Lowe et al., 1993; Miyashita et al., 1994). In many cell types, intrinsic apoptosis is regulated by the expression ratio of cell death inhibitor proteins, including Bcl-2, and cell death inducer proteins, such as Bax (Oltvai et al., 1993; Miyashita et al., 1994; Reed, 1994; Sedlak et al., 1995; Cory et al., 2003). This mechanism has been referred to as the rheostat hypothesis (Korsmeyer, 1995). In healthy cells, Bcl-2 is present on the surface of mitochondrial outer membranes and prevents apoptotic induction by blocking the actions of Bax and related proteins. Intrinsic apoptotic induction alters the "rheostat", shifting in favor of Bax and related proteins. This ultimately results in a loss of the inner mitochondrial transmembrane potential and causes Bcl-2 to dissociate from the membrane and release cytochrome $c$ into the cytoplasm (Kluck et al., 1997). The released cytochrome $c$ forms a heterodimer with the Apaf-1 protein which triggers the formation of the apoptosome, approximately a $1 \mathrm{MDa}$ oligomeric complex containing seven molecules each of Apaf-1, cytochrome $c$, ATP, and caspase 9 (Zou et al., 1997; Waterhouse et al., 2002). The formation of the apoptosome activates caspase 9 cleave other caspases, triggering an expanding caspase cascade that leads to the digestion of structural proteins in the cytoplasm, degradation of chromosomal DNA, and phagocytosis of the cell (Thornberry and Lazebnik, 1998).

A caspase-independent mechanism of intrinsic apoptotic induction has also been identified (Hunot and Flavell, 2001; Joza et.al., 2001). This pathway utilizes neither initiator nor effector caspases, but rather is mediated by the nuclear effector, apoptosis inducing factor (AIF), which directly triggers chromatin condensation and DNA fragmentation in the nucleus. This pathway, like the caspase-dependent intrinsic pathway, is suppressed by the antiapoptotic protein Bcl-2.

Extrinsic, or "death" receptor mediated apoptosis is initiated when a soluble ligand (such as tumor necrosis factor, TNF; Fas ligand, FasL; or TNF-related apoptosis-inducing ligand, TRAIL) binds to specific receptors on the cell surface (Nagata, 1997; Ashkenazi and Dixit, 1998). Upon ligand binding, the assembly of the death-inducing signaling complex (DISC, a complex composed of Fas, FasL, FADD, and procaspase 8 ) is triggered and leads to the activation of 
INTRINSIC

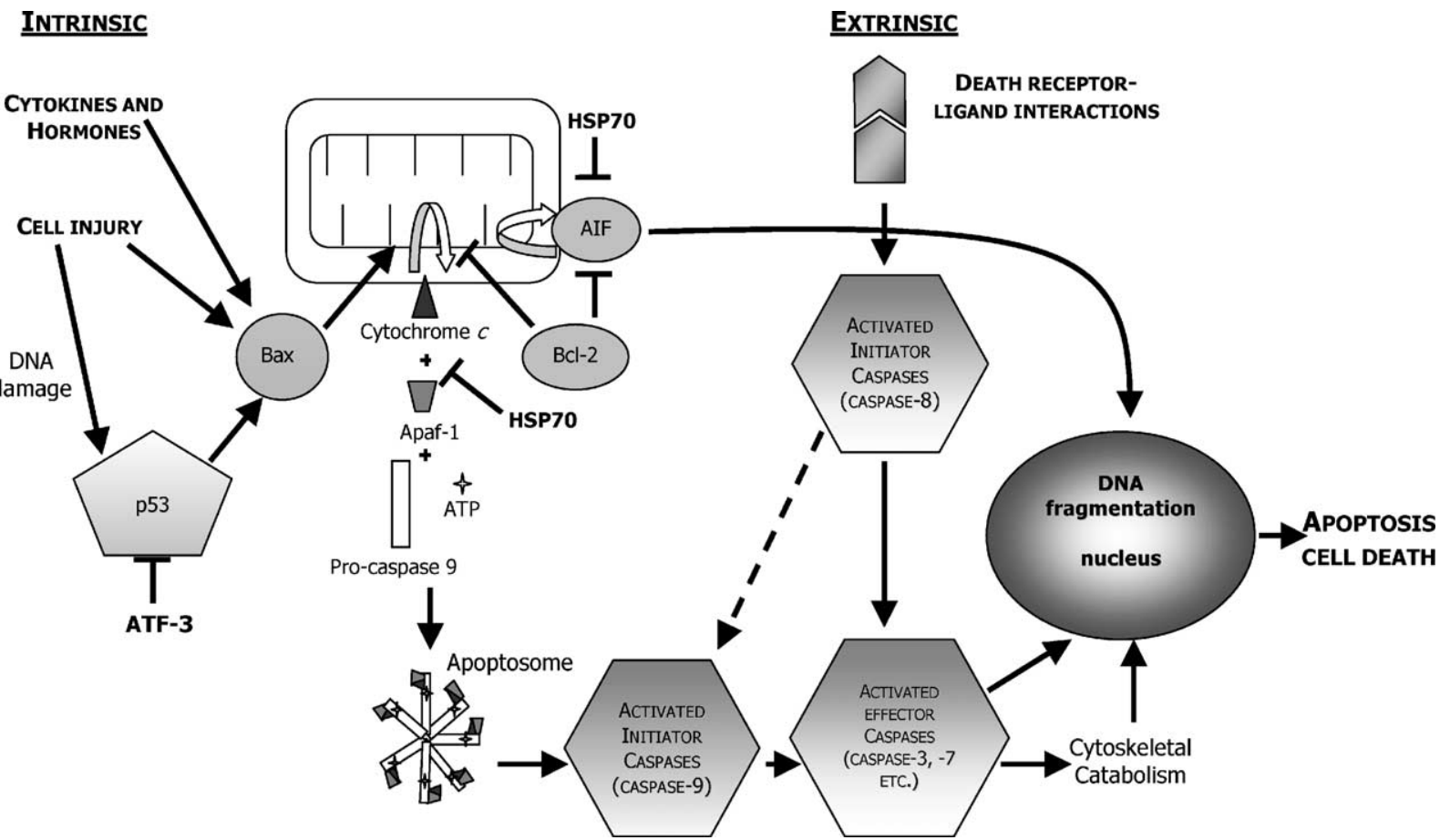

Fig. 1. Intrinsic and extrinsic apoptotic pathways. Apoptotic pathways as discussed in this review in regards to PRRSV-infection of MARC-145 cells. Lines with arrows denote an activating reaction, lines ending in perpendicular lines denote inhibition of the reaction, and dotted lines denote uncertainty of the reaction.

caspase 8. Caspase 8 (like caspase 9) initiates a cascade of caspase activation leading to phagocytosis of the cell (Ashkenazi, 2002).

Both the intrinsic and extrinsic apoptosis pathways, other than the AIF-dependent pathway, utilize "initiator" caspases (e.g., caspase 8 or 9) to activate "effector" caspases (e.g., caspase 3 or 7). Caspases are synthesized as pro-enzymes that must undergo proteolytic processing to become activated. Activation of initiator caspases triggers a cascade of caspase activation, ultimately leading to the activation of caspase 3 (Earnshaw et al., 1999). Upon activation, caspase 3 is capable of cleaving many important cellular substrates leading to inactivation of critical DNA repair enzymes, activation of specific nucleases, and changing the cytoskeleton of the nucleus and cytoplasm leading to DNA cleavage and nuclear collapse (Nicholson et al., 1995).

Apoptosis is often modulated in the pathogenesis of infectious diseases. Inhibition of apoptosis may benefit intracellular viruses by prolonging their survival. Viruses that produce dsRNA as part of their replication cycle directly trigger apoptosis in infected cells. Many viruses have adapted by encoding antiapoptotic gene products that permit their seemingly undetected replication. Some viruses (e.g., African Swine Fever Virus, ASFV) encode proteins that prevent apoptosis through inactivation of p53 or binding of Bax (Neilan et al., 1993; Afonso et al., 1996; Brun et al., 1996; Revilla et al., 1997; Young et al., 1997). Yet other viruses (such as Baculovirus) possess mechanisms to inhibit apoptosis by expressing caspase inhibitors that interfere with caspase function (Manji and Friesen, 2001). Thus, viruses have evolved numerous mechanisms acting at many different points in the induction to interfere and block apoptosis.

\subsection{Necrosis}

The other mechanism of cell death due to viral infection is necrosis. Necrosis is the pathological process which occurs when cells are exposed to a variety of detrimental stimuli (Majno and Joris, 1995). Necrosis was long thought to be an uncontrolled, 
irreversible process; however, more recent studies have shown that necrosis is highly regulated and a fine regulatory line exists between necrosis and apoptosis (Plymale et al., 1999; Proskuryakov et al., 2002, 2003; Syntichaki and Tavernarakis, 2002). Necrosis begins with damage to the plasma membrane impairing the cell's ability to maintain homeostasis, leading to an influx of water and extracellular $\mathrm{Ca}^{2+}$ ions. To this point, the process is reversible. Irreversible cellular necrosis is associated with swelling of intracellular organelles, most notably the mitochondria, and the entire cell swells and ruptures (cell lysis). With breakdown of the plasma membrane, the cytoplasmic contents (including lysosomal enzymes) leak out into the extracellular fluid, which is why necrotic cell death is often associated with extensive tissue damage and an intense inflammatory response (Schwartz et al., 1993).

\subsection{Apoptosis and arteriviruses}

Equine arteritis virus (EAV) is the prototype virus of the Arteriviridae. Archambault and St-Laurent (2000) have shown that EAV induces apoptosis of infected cells in vitro without inhibiting viral multiplication, and the EAV-induced apoptotic process (fragmentation of chromosomal DNA into nucleosomal oligomers and caspase activation) correlates with the appearance of cytopathic effect (CPE) (Archambault and St-Laurent, 2000). Studies examining this effect in vivo have not been published to confirm that a similar response occurs within infected animals.

\subsubsection{Apoptosis and PRRSV}

There are a number of published studies examining PRRSV infection and apoptosis. Despite the large body of work in this area, there is still conflicting evidence and views as to whether PRRSV induces apoptosis directly (within infected cells) or indirectly (within bystander cells). However, it is clear that within both infected tissue cultured cells and animals, apoptotic cells are observed and contribute to the pathology observed in the animal. In the next few paragraphs, we will summarize published studies pertaining to PRRSV and apoptosis.

The first report of apoptosis related to PRRSV was by Suarez et al. (1996). Expression of the PRRSV GP 5 (ORF5) gene in monolayers of cells using a vaccinia virus expression vector induced apoptosis, while the vaccinia vector alone did not. In addition, the study demonstrated similar apoptosis induction in both PRRSV-infected cultured cells and macrophages from infected pigs. The $\mathrm{GP}_{5}$-induced apoptosis was not prevented in cells stably expressing the Bcl-2 protein, leading the authors to conclude that the PRRSVspecific induction of apoptosis must be occurring downstream of Bcl-2 in the apoptosis cascade or by a yet undetermined pathway. The apoptotic inducing region of $\mathrm{GP}_{5}$ has been mapped to the N-terminal 119 amino acids by Fernandez et al. (2002), using vectors that enabled transient expression of $\mathrm{GP}_{5}$ concurrently with reporter genes (luciferase and CAT). Recently, Gagnon et al. (2003) expressed the $\mathrm{GP}_{5}$ protein using an adenovirus expression system and detected an increase in caspase 3 activity in cell monolayers transfected with the vector. In addition, DNA fragmentation was evident within the monolayer. Together, these reports demonstrate that artificial expression of $\mathrm{GP}_{5}$ using viral vectors can induce apoptosis within monolayers of cells, but the mechanism of induction (direct or indirect) has not been definitively elucidated.

During infection of pigs with PRRSV, apoptotic cells are found widely distributed within infected tissues (including: lungs, testes, and lymph nodes). Sur et al. (1997) demonstrated that in acutely infected boars there was significant depletion of germ cells within the testis. Furthermore, it was shown that germ cell death occurred by apoptosis as detected by in situ TUNEL assays. The study was not able to determine conclusively if cells undergoing apoptosis were also infected with PRRSV. An additional study by Sur et al. (1998), examined whether PRRSV-induced apoptosis occurred as a direct result of virus infection. The study demonstrated widespread apoptosis in lungs and lymphoid tissues of young pigs using immunohistochemical methods, TUNEL, DNA gel electrophoresis, and electron microscopy. However, the study ultimately concluded that the majority of apoptotic cells were not infected with PRRSV. Sirinarumitr et al. (1998) reported similar results when infecting young pigs with PRRSV. Apoptotic cells were identified based upon ultrastructural morphology and in situ TUNEL assays. However, upon performing dual labeling experiments it was concluded that the majority of apoptotic cells were not infected with 
PRRSV. A similar finding was reported by Labarque et al. (2003) when, utilizing dual-labeling methods, they found that the majority of apoptotic cells collected during lavage of infected piglets were not infected.

Using a double-labeling procedure for the detection of PRRSV and in situ TUNEL assay for the detection of apoptosis in infected pig lungs, Choi and Chae (2002) demonstrated that a majority of labeled cells were infected with PRRSV or apoptotic, but not both. Additionally, double-labeling for the TNF-alpha and in situ TUNEL assay for the detection of apoptosis demonstrated that cells were apoptotic or positive for TNF-alpha, but not both. The authors suggest that TNF-alpha released from macrophages after infection by PRRSV may be the causative inducer of apoptosis in uninfected bystander cells. Oleksiewicz and Nielsen (1999) showed that PRRSV-infection of in vitro cultured swine alveolar macrophages led to a $40 \%$ reduction in the number of viable cells at $48 \mathrm{~h}$ postinfection, but the surviving cells exhibited normal phagocytic ability. In comparison to living cells, dead cells were shown to have a two-fold reduction in forward light scattering, a measure of cell size. The study used this method for the detection of apoptosis along with flow cytometric analysis of propidium iodide stained cells to detect reductions in DNA content. It is important to note that both apoptosis and necrosis can result in the reduction of cell size and DNA content and that the methods used in this study could not have differentiated between the two processes. Finally, a study by Feng et al. (2002) showed by the TUNEL method that the number of apoptotic thymocytes was increased two-fold in PRRSV-infected piglets. The study did not attempt to examine the apoptotic cells for the presence of a replicating virus.

In addition to in vivo infection, apoptosis has been reported within in vitro infected cells (Sirinarumitr et al., 1998; Kim et al., 2002). A "nontypical” form of apoptosis has been described by Kim et al. (2002) in PRRSV-infected MARC-145 cells (African green monkey kidney cells). At 3 days post-infection, infected cells were observed detaching from the flask surface and undergoing apoptosis, as evidenced by nuclear condensation and inter-nucleosomal DNA fragmentation. Co-localization of both PRRSV antigen and apoptosis (using TUNEL assay, which detects nicked DNA ends) was evident within these cells and provides, perhaps, the strongest evidence to date that PRRSV is capable of directly inducing apoptosis. It is important to note that the study also showed that the majority of these cells were necrotic, as evidenced by trypan blue uptake. Given these results, it is important to consider the possibility that the DNA fragmentation may have resulted from necrosis, as documented in other systems (van Lookeren Campagne et al., 1995). Yet, another possibility is that these cells are indeed undergoing apoptosis mediated through the AIFdependent pathway that does not result in "typical" apoptosis (Fig. 1). Sirinarumitr et al. (1998) reported that PRRSV infection of the American Type Culture Collection (ATCC) CRL 11171 cells (another African green monkey kidney cell line) resulted in apoptosis, as evidenced by electron microscopy, TUNEL, and double-labeling methods. Unlike the report by Kim et al. (2002), this study determined that apoptotic cells were primarily uninfected or bystander cells in the monolayer. The techniques used in this study would have only permitted examination of adherent cells in the monolayer, not floating cells, which may account for the differing conclusions between the two studies.

The majority of published work supports a mechanism of apoptotic induction by indirect (extrinsic) induction in bystander cells. However, this has not been proven conclusively and further investigation is warranted. In particular, there is a need to examine pro-apoptotic gene expression during PRRSV infection. The induction of apoptosis is a highly regulated process involving a cascade of known genes. Examining the expression of genes in this cascade will permit the differentiation between apoptotic and necrotic induction, whereas, methods such as the TUNEL assay, which detect events occurring late in the process and similar to both processes, are unable to differentiate. In addition, examination of virus load (multiplicity of infection) is imperative, given several studies have documented both apoptotic and necrotic cell deaths by the same virus with varying levels of viral exposure (Plymale et al., 1999; Rasilainen et al., 2004). To this end, we have conducted experiments examining the expression of apoptosis-related genes during PRRSV infection of MARC-145 cells using microarray methodology in conjunction with detection of nucleosomal fragmentation of DNA in cells exposed to varying levels of virus. 


\section{Results}

Monolayers of MARC-145 cells were infected with PRRSV isolate $16244 \mathrm{~b}$ at a high multiplicity of infection $(\mathrm{moi}=10)$ to maximize the number of infected cells and minimize the affect of uninfected cells on the analysis. It is imperative to have all (or as many possible) cells infected when trying to determine if PRRSV infection is directly inducing apoptosis. Cells were monitored for virus replication by sqRTPCR and immunofluorescent staining for PRRSV antigen. Cell monolayers displayed greater than $87 \%$ of the cells infected with PRRSV and showed dramatic increases in both positive-stranded (236-fold) and negative-stranded (32-fold) RNA detection between 16 and $48 \mathrm{~h}$ infection (data not shown). Cells were harvested at 2, 6, 10, 16, and $24 \mathrm{~h}$ post-infection, mRNA harvested and labeled, and microarray analysis performed using the LifeArray V2.34 (Incyte Genomics, St. Louis, MO) containing over 9200 genes. All 9200 genes were analyzed in relation to mock infected time controls. Using numerous internal controls, Incyte Genomics calculated that genes with expression changes of greater than 2.5-fold were significantly different using these arrays. Thus, all genes in which the mRNA levels differed by 2.5 -fold or more between mock and PRRSV-infected samples were significantly changed as a result of infection. The data set was selectively queried such that genes involved in apoptosis were analyzed as a unique set (Fig. 2, Table 1) using the software package GeneSpring (Silicon Genetics, Redwood City, CA). The 26 genes analyzed did not show significant alteration over the $24 \mathrm{~h}$ time course performed. In addition, semi-quantitative real-time reverse transcription polymerase chain reaction (sqRT-PCR) of several genes at $48 \mathrm{~h}$ post-infection showed no difference from the $24 \mathrm{~h}$ results (data not shown). Thus, PRRSV-infection does not induce apoptotic gene expression.

To ensure we were not missing apoptotic induction by only examining transcript levels, we examined the cellular and extracellular fractions of the cellular monolayers for free histone-associated DNA fragments in both the cellular fraction (apoptosis) and extracellular or supernatant fraction (necrosis) using the Cell Death Detection ELISA ${ }^{\text {PLUS }}$ Kit (Roche Molecular Biochemical, Indianapolis, IN). Fig. 3,

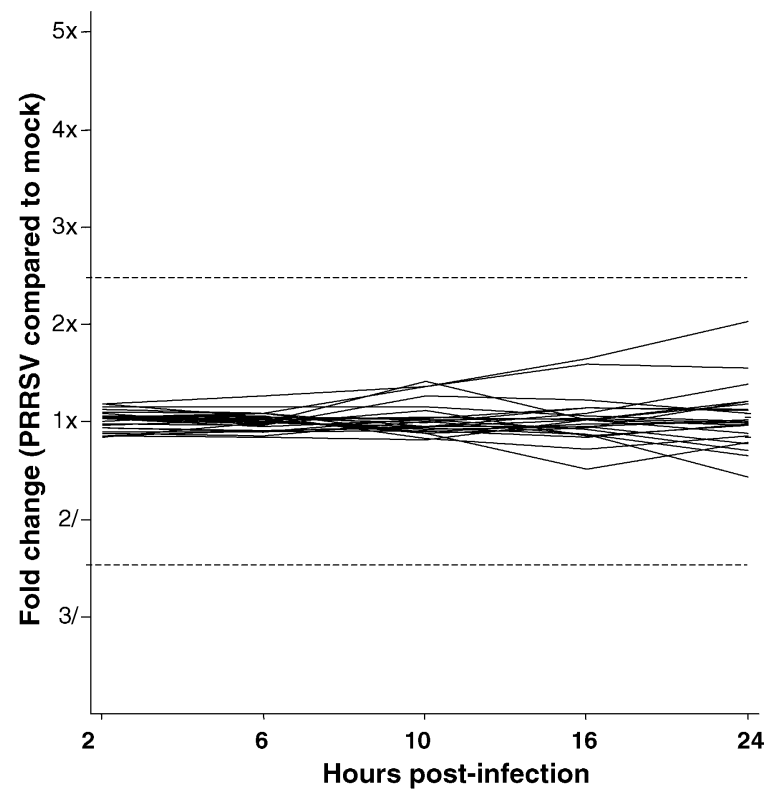

Fig. 2. Expression of apoptotic gene transcripts in PRRSV-infected MARC-145 cells. Transcript profiles of MARC-145 cell response to PRRSV infection were examined in MARC-145 cells infected with PRRSV at an moi of 10. Cells were collected at 2, 6, 10, 16, and $24 \mathrm{~h}$ post-infection, poly-A RNA isolated, and assayed using the LifeArray V2.34 (Incyte Genomics, Palo Alto, CA). Significant change in gene expression is 2.5 (dotted lines). Mock-infected cells were used as comparative samples.

Panel A, shows the proportion of necrotic and apoptotic MARC-145 cells following infection with PRRSV (using a moi of $0.1,1$, and 10) compared with mock-infected and cyclohexamide (known intrinsic inducer of apoptosis) controls. Levels of viral RNA accumulation, as measured by sqRT-PCR, were consistent with the virus moi utilized to infect the cells at $24 \mathrm{~h}$ post-infection, and were at similar levels by $48 \mathrm{~h}$ post-infection (data not shown). At $24 \mathrm{~h}$ postinfection, a clear induction of necrosis in PRRSVinfected cells is evident and increases as the virus moi increases. Only minimal increases in the apoptotic indicator occurred between mock-infected and PRRSV-infected cells, despite the amount of virus inoculum utilized. Similar results were determined at $48 \mathrm{~h}$ post-infection (Fig. 3, Panel B). Necrosis was prevalent, regardless of treatment, while apoptotic indicator levels were much lower and similar across all cellular treatments. These results indicate that necrosis, more so than apoptosis, contributes to cell death induced by PRRSV. 
Table 1

Apoptosis genes examined in microarray experiment (Fig. 2)

\begin{tabular}{|c|c|c|}
\hline Gene name $^{\mathrm{a}}$ & Accession number & $24 \mathrm{~h} \mathrm{data}^{\mathrm{b}}$ \\
\hline Apoptosis inhibitor 5 & U83857 & 0.975 \\
\hline Survivin & NM_004920 & 1.089 \\
\hline Baculoviral IAP repeat-containing 5 (survivin) & NM_013229 & 0.775 \\
\hline CASP8 and FADD-like apoptosis regulator & $\mathrm{U} 75285$ & 0.826 \\
\hline Caspase 2, apoptosis-related cysteine protease & AF077350 & 0.876 \\
\hline PRKC, apoptosis, WT1, regulator & BE513972 & 0.961 \\
\hline PRKC, apoptosis, WT1, regulator & U13698 & 0.993 \\
\hline Apoptotic protease activating factor & U13022 & 0.741 \\
\hline Caspase 1 , apoptosis-related cysteine protease & U13738 & 0.998 \\
\hline Caspase 10 , apoptosis-related cysteine protease & U25804 & 1.384 \\
\hline Caspase 3, apoptosis-related cysteine protease & $\mathrm{U} 28015$ & 1.21 \\
\hline Caspase 4 , apoptosis-related cysteine protease & U20536 & 0.864 \\
\hline Caspase 5 , apoptosis-related cysteine protease & U37448 & 0.96 \\
\hline Caspase 6 , apoptosis-related cysteine protease & U60520 & 1.047 \\
\hline Caspase 7 , apoptosis-related cysteine protease & U60521 & 0.992 \\
\hline Caspase 8 , apoptosis-related cysteine protease & AI874357 & 1.179 \\
\hline Caspase 9 , apoptosis-related cysteine protease & AA527277 & 0.636 \\
\hline Modulator of apoptosis 1 & AW960701 & 1.092 \\
\hline Requiem, apoptosis response zinc finger gene & BE384951 & 1.546 \\
\hline Secreted frizzled-related protein 5 & AF017988 & 1.014 \\
\hline Serine/threonine kinase 17a (apoptosis-inducing) & NM_004760 & 0.889 \\
\hline Serine/threonine kinase $17 \mathrm{~b}$ (apoptosis-inducing) & AW172382 & 1.212 \\
\hline TGFB1-induced anti-apoptotic factor 1 & AA402957 & 1.117 \\
\hline Tumor necrosis factor (ligand) superfamily, member 6 & NM_000639 & 1.132 \\
\hline Tumor necrosis factor receptor superfamily, member $10 \mathrm{~b}$ & AF016268 & 2.032 \\
\hline Apoptosis associated tyrosine kinase (AATYK) & NM_001230 & 0.819 \\
\hline
\end{tabular}

${ }^{a}$ If gene is unnamed, function is listed.

b Normalized differential expression of PRRSV-infected cells in comparison to mock-infected cells at $24 \mathrm{~h}$ post-infection.

The results shown in Fig. 3 indicate a low, variable level of apoptosis in PRRSV-infected cells. This same effect, not evident in $24 \mathrm{~h}$ mock treated cells, was seen in $48 \mathrm{~h}$ mock treated cells. This raised the possibility that length of time in culture may be triggering apoptosis at a low level in MARC-145 cells. Given that all virus stocks utilized were prepared from $72 \mathrm{~h}$ infections containing virus in "spent" culture medium, we examined the effect of "spent" culture media (i.e., media harvested from cells at $72 \mathrm{~h}$ in a manner similar to virus preparations, on MARC-145 cells). Fig. 4 shows that "spent" culture media alone induces low levels of apoptosis, as well as cellular necrosis when compared to cells cultured in "fresh" media. This low level of apoptosis is at a similar level to that seen in the PRRSV-infected cells in Fig. 3. Thus, factors present in $72 \mathrm{~h}$ culture media from MARC-145 cells are capable of inducing low-level apoptosis in the cell monolayers, independent of virus infection.

\section{Discussion}

Transcriptional profiling using microarrays and sqRT-PCR has enabled us to accurately quantify the effect of PRRSV infection on MARC-145 cell gene expression. Analysis of the 26 apoptosis-related genes over the $24 \mathrm{~h}$ time course of infection, displayed little to no change in transcript abundance, indicating that apoptosis is not being induced in these cells. Apoptosis, once induced, can be completed within 30-60 min and necrosis within $24 \mathrm{~h}$ (Majno and Joris, 1995). Our results suggest that apoptotic gene expression is not occurring within the first $24 \mathrm{~h}$ of infection, in spite of the fact that PRRSV is replicating to high levels. Remaining to be answered is whether PRRSV actively interferes with the induction or simply does not induce apoptosis.

It is interesting, to speculate on whether or not PRRSV actively interferes with the induction of apoptosis. Previous studies in our laboratory have 

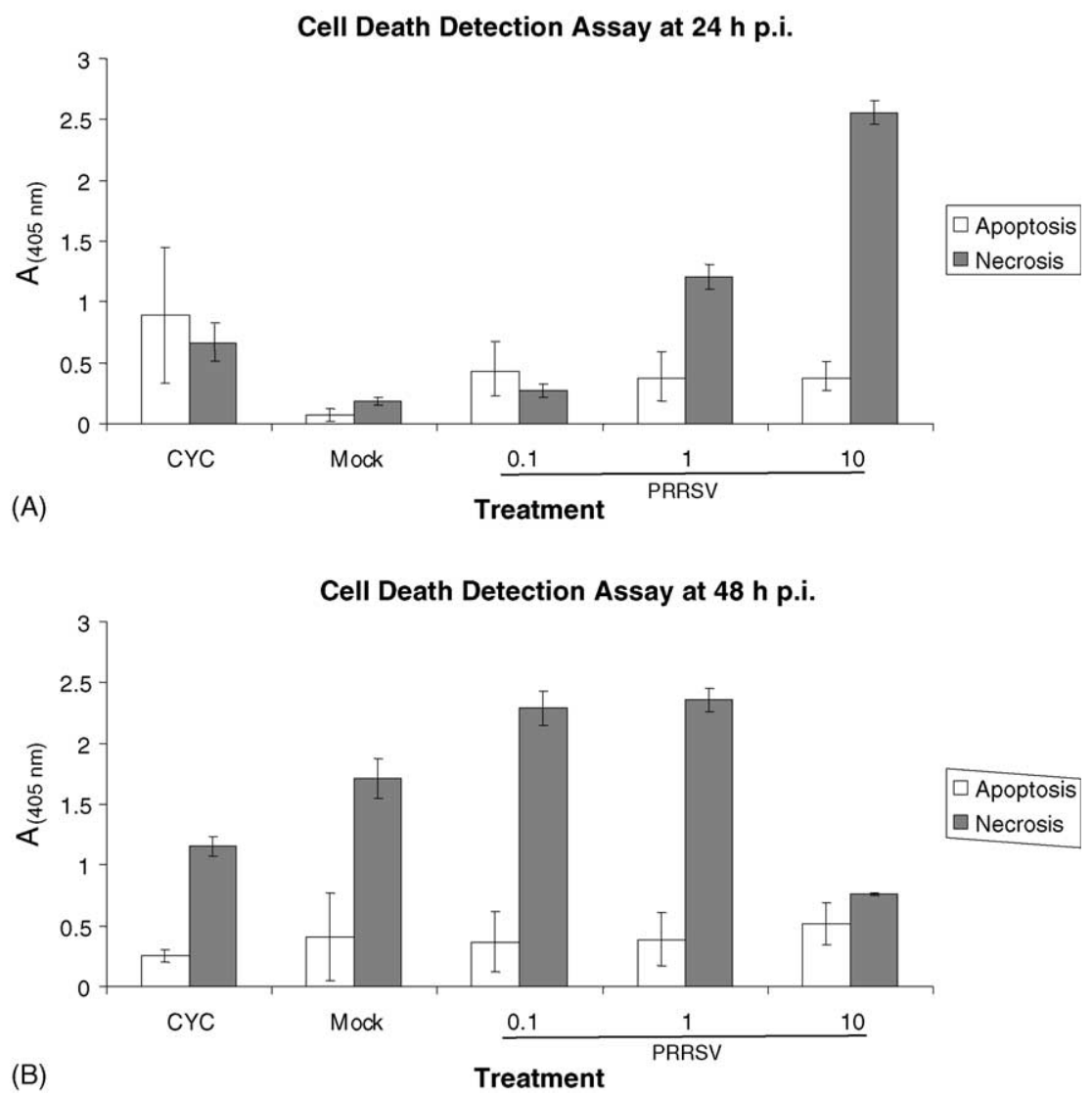

Fig. 3. Induction of apoptosis vs. necrosis in PRRSV-infected MARC-145 cells. MARC-145 cells were trypinized, washed, seeded (10 4 cells/ well) in a 96-well flat-bottomed microtiter plate, and grown at $37{ }^{\circ} \mathrm{C}, 5 \% \mathrm{CO}_{2}$ for $16 \mathrm{~h}$. The cells were infected in triplicate with PRRSV isolate $16244 \mathrm{~b}$ in declining multiplicity of infection of 10,1 , and 0.1 . Virus was applied to confluent monolayers in chilled MEM media and permitted to adhere at $4{ }^{\circ} \mathrm{C}$ for $1 \mathrm{~h}$, then pre-warmed MEM media with $5 \%$ fetal calf serum (FCS) was added, and the cells were placed at $37{ }^{\circ} \mathrm{C}, 5 \% \mathrm{CO}_{2}$ and humidification. Mock-infected cells were treated with cell culture MEM medium without PRRSV as a negative control. The cells were incubated for 24 (Panel A) or $48 \mathrm{~h}$ (Panel B), centrifuged $10 \mathrm{~min}$ with $200 \times \mathrm{g}$, and the supernatant retained for necrosis analysis. The cell pellet was resuspended in $200 \mu \mathrm{l}$ Lysis buffer ( $10 \mathrm{mM}$ EDTA, pH 8), incubated $30 \mathrm{~min}$ at $15-25^{\circ} \mathrm{C}$ for cell lysis. After lysis, cells were centrifuged and $20 \mu \mathrm{l}$ from the supernatant (cytoplasmic fraction) was transferred into streptavidin coated microplates for analysis in the Cell Death Detection ELISA $^{\text {PLUS }}\left(1 \times 10^{3}\right.$ cell equivalents/well $=5 \times 10^{3}$ cell equivalents $\left./ \mathrm{ml}\right)$. One hundred micrometers of cycloheximide was added to MARC145 cells for 24 and $48 \mathrm{~h}$ as a positive inducer of apoptosis.

shown that PRRSV inhibits type-I IFN mRNA synthesis induced by yeast tRNA, a form of dsRNA that mimics vRNA-induction of innate immune responses (Miller et al., 2004). A number of reports suggest that triggering and executing virus-induced apoptosis and type-I IFN synthesis occur via common pathways. Specifically, IFN- $\alpha / \beta$ are essential mediators or potentiators of apoptotic death in virus-infected cells (Tanaka et al., 1998; Balachandran et al., 2000). Critical enzymes needed early in the induction of both the type I IFN and apoptosis pathways are PKR and $2^{\prime} 5^{\prime}$ - oligoadenylate synthetase (Zhou et al., 1997; Kaufman, 1999; Tan and Katze, 1999; Gil and Esteban, 2000). Transcript levels for both of these genes are unchanged in PRRSV infected MARC-145 cells (unpublished data). This suggests that the cellular detection of dsRNA, an early event in the cascade, is being suppressed in PRRSV infected cells and, therefore, preventing induction of the innate immune response.

In contrast, the lack of apoptotic induction may not be due to a direct interference mechanism, but rather an indirect mechanism by PRRSV infection. We have 
Cell Death Detection Assay at $24 \mathrm{~h}$ p.i.

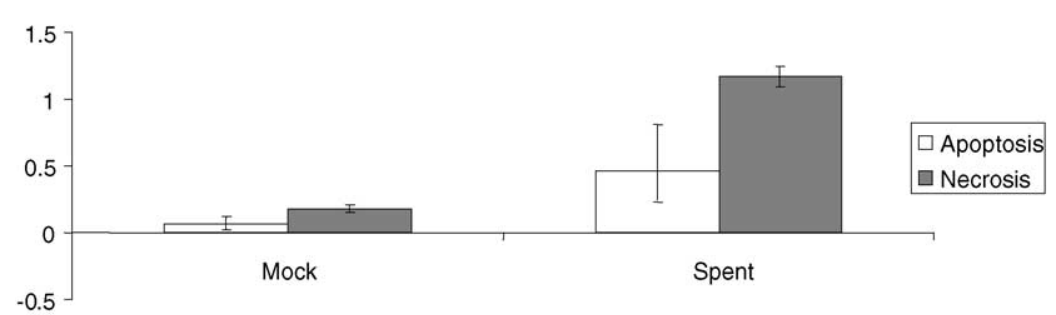

(A)

Treatment

Cell Death Detection assay at $48 \mathrm{~h}$ p.i.

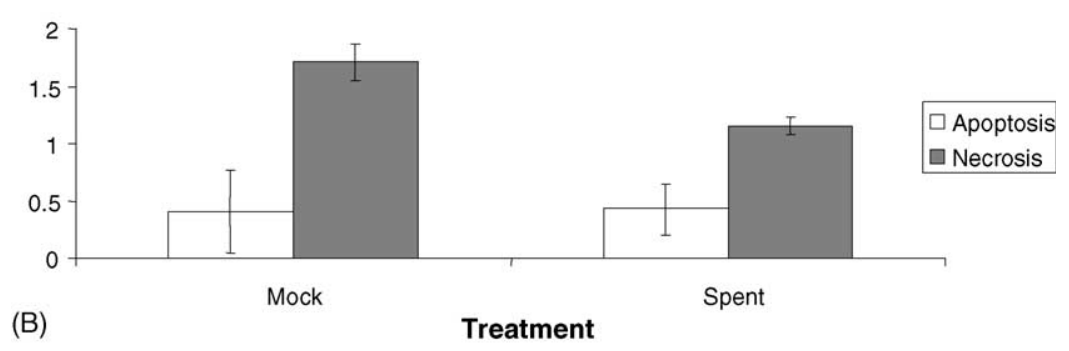

Fig. 4. Comparison of fresh vs. spent media on apoptotic and necrotic induction. MARC- 145 cells $\left(1 \times 10^{4}\right.$ cells/well $)$ were treated, in triplicate, for $24 \mathrm{~h}$ (Panel A) and $48 \mathrm{~h}$ (Panel B) with fresh or spent media. Before and after lysis, cells were centrifuged and the supernatants were analyzed in the Cell Death Detection ELISA ${ }^{\text {PLUS }}\left(1 \times 10^{3}\right.$ cell equivalents $/$ well $=5 \times 10^{3}$ cell equivalents $\left./ \mathrm{ml}\right)$.

evidence that two of the most changed and abundantly expressed genes resulting from PRRSV infection of MARC-145 cells are ATF-3 and Hsp70 (13.8- and 11.7-fold increase at $24 \mathrm{~h}$ post-infection, data not shown). As shown in Fig. 1, both activation transcription factor ATF-3 and Hsp70 are potent suppressors of the apoptotic pathway. ATF-3 is a transcriptional suppressor of the p53 gene and Hsp70 interferes with the dimerization of Apaf- 1 and cytochrome $c$ and is an antagonist to the AIF apoptotic pathway (Kim et al., 1995, 1997; Garrido et al., 2001; Ravagnan et al., 2001; Zhang et al., 2002). The significant upregulation of ATF-3 and Hsp70 could result in the complete blocking of the intrinsic apoptosis pathway. Perhaps, PRRSV takes advantage of both mechanisms to ensure that viral replication goes unnoticed within the cell and prevents apoptotic induction.

The detection of free nucleosomal fragments in the culture media at both 24 and $48 \mathrm{~h}$ post-infection indicate there is significant cellular lysis (necrosis) occurring in PRRSV-infected cells. This, combined with only low, variable levels of cell-associated nucleosomal fragments, suggests that apoptosis is not occurring at significant levels within the infected monolayer. We performed the experiment with different virus inocula to see if we could detect increased apoptosis in the monolayers infected with fewer viruses, a measure of the "bystander cell" effect. We did not observe a measurable correlation. However, we did see a direct correlation with the amount of virus inoculum and the level of necrosis detected at $24 \mathrm{~h}$ post-infection.

The observation that mock-infected cells at $24 \mathrm{~h}$ displayed much less background apoptosis than the same cells at $48 \mathrm{~h}$ led us to conclude that $48 \mathrm{~h}$ cells perhaps were undergoing apoptosis as a result of longer culturing. We hypothesized that there may be soluble factors present in the culture supernatant capable of inducing apoptosis, and these same factors would be present in virus stock preparations which are harvested at $72 \mathrm{~h}$ post-infection. Increased levels of both apoptosis and necrosis in those cells exposed to "spent" media suggests that soluble factors are present in the media that act as potentiators of these two processes. Apoptotic and necrotic regulatory mechanisms share common features and perhaps, in 
these experiments, the soluble mediators triggering these processes are similar-if not the same (Bonfoco et al., 1995; Shimizu et al., 1996). This finding has important implications on much of the work performed on PRRSV using in vitro cultured cells. Perhaps, the apoptosis identified in these studies is due to factors independent of PRRSV infection.

\section{Conclusion}

It is clearly evident that apoptotic cells can be found both in vitro and in vivo during PRRSV infection. It is also apparent that apoptotic cells contribute to the pathogenesis of the infection in pigs. What remains to be answered is whether PRRSV infection directly leads to the induction of apoptosis. Our data suggest that PRRSV does not directly induce an apoptotic gene expression response and results in vastly more necrotic cell death than apoptotic cell death within monolayers of MARC-145 infected cells. In addition, through our work and others, there seems to be accumulating evidence suggesting that PRRSV interferes with the induction of the cellular innate immune response, pathways of which are tied closely with that of apoptosis (apoptosis is more increasingly being classified as an innate immune response). This may explain why there is a delayed immune response in PRRSV-infected pigs and elucidation of the mechanisms of interference may provide clues into novel intervention strategies to combat PRRSV infection.

\section{Acknowledgements}

The authors would like to acknowledge Drs. Michael Clawson, William Laegreid, Dan Nonneman, and Fernando Osorio for helpful discussions and reviewing of the manuscript. We would like to thank Geoffrey Hirsch and Tammy Sorensen for excellent technical assistance and Joan Rosch for secretarial assistance in preparation of the manuscript.

\section{References}

Afonso, C.L., Neilan, J.G., Kutish, G.F., Rock, D.L., 1996. An African swine fever virus Bc1-2 homolog, 5-HL, suppresses apoptotic cell death. J. Virol. 70, 4858-4863.
Archambault, D., St-Laurent, G., 2000. Induction of apoptosis by equine arteritis virus infection. Virus Genes 20, 143-147.

Ashkenazi, A., 2002. Targeting death and decoy receptors of the tumour-necrosis factor superfamily. Nat. Rev. Cancer 2, 420430.

Ashkenazi, A., Dixit, V.M., 1998. Death receptors: signaling and modulation. Science 281, 1305-1308.

Balachandran, S., Roberts, P.C., Brown, L.E., Truong, H., Pattnaik, A.K., Archer, D.R., Barber, G.N., 2000. Essential role for the dsRNA-dependent protein kinase PKR in innate immunity to viral infection. Immunity 13, 129-141.

Bonfoco, E., Krainc, D., Ankarcrona, M., Nicotera, P., Lipton, S.A., 1995. Apoptosis and necrosis: two distinct events induced, respectively, by mild and intense insults with $N$-methyl-D-aspartate or nitric oxide/superoxide in cortical cell cultures. Proc. Natl. Acad. Sci. U.S.A. 92, 7162-7166.

Brun, A., Rivas, C., Esteban, M., Escribano, J.M., Alonso, C., 1996. African swine fever virus gene A179L, a viral homologue of Bcl-2, protects cells from programmed cell death. Virology 225 , 227-230.

Choi, C., Chae, C., 2002. Expression of tumour necrosis factor-alpha is associated with apoptosis in lungs of pigs experimentally infected with porcine reproductive and respiratory syndrome virus. Res. Vet. Sci. 72, 45-49.

Cory, S., Huang, D.C., Adams, J.M., 2003. The Bcl-2 family: roles in cell survival and oncogenesis. Oncogene 22, 85908607.

Dypbukt, J.M., Ankarcrona, M., Burkitt, M., Sjoholm, A., Strom, K., Orrenius, S., Nicotera, P., 1994. Different prooxidant levels stimulate growth, trigger apoptosis, or produce necrosis of insulin-secreting RINm5F cells. The role of intracellular polyamines. J. Biol. Chem. 269, 30553-30560.

Earnshaw, W.C., Martins, L.M., Kaufmann, S.H., 1999. Mammalian caspases: structure, activation, substrates, and functions during apoptosis. Annu. Rev. Biochem. 68, 383-424.

Feng, W.H., Tompkins, M.B., Xu, J.S., Brown, T.T., Laster, S.M., Zhang, H.X., McCaw, M.B., 2002. Thymocyte and peripheral blood T lymphocyte subpopulation changes in piglets following in utero infection with porcine reproductive and respiratory syndrome virus. Virology 302, 363-372.

Fernandez, A., Suarez, P., Castro, J.M., Tabares, E., Diaz-Guerra, M., 2002. Characterization of regions in the GP5 protein of porcine reproductive and respiratory syndrome virus required to induce apoptotic cell death. Virus Res. 83, 103-118.

Gagnon, C.A., Lachapelle, G., Langelier, Y., Massie, B., Dea, S., 2003. Adenoviral-expressed GP5 of porcine respiratory and reproductive syndrome virus differs in its cellular maturation from the authentic viral protein but maintains known biological functions. Arch. Virol. 148, 951-972.

Garrido, C., Gurbuxani, S., Ravagnan, L., Kroemer, G., 2001. Heat shock proteins: endogenous modulators of apoptotic cell death. Biochem. Biophys. Res. Commun. 286, 433-442.

Gil, J., Esteban, M., 2000. Induction of apoptosis by the dsRNAdependent protein kinase (PKR): mechanism of action. Apoptosis 5, 107-114.

Hetts, S.W., 1998. To die or not to die: an overview of apoptosis and its role in disease. J. Am. Med. Assoc. 279, 300-307. 
Hunot, S., Flavell, R.A., 2001. Apoptosis. Death of a monopoly? Science 292, 865-866.

Joza, N., Susin, S.A., Daugas, E., Stanford, W.L., Cho, S.K., Li, C.Y., Sasaki, T., Elia, A.J., Cheng, H.Y., Ravagnan, L., Ferri, K.F., Zamzami, N., Wakeham, A., Hakem, R., Yoshida, H., Kong, Y.Y., Mak, T.W., Zuniga-Pflucker, J.C., Kroemer, G., Penninger, J.M., 2001. Essential role of the mitochondrial apoptosis-inducing factor in programmed cell death. Nature 410, 549-554.

Kaufman, R.J., 1999. Double-stranded RNA-activated protein kinase mediates virus-induced apoptosis: a new role for an old actor. Proc. Natl. Acad. Sci. U.S.A. 96, 11693-11695.

Kerr, J.F., Wyllie, A.H., Currie, A.R., 1972. Apoptosis: a basic biological phenomenon with wide-ranging implications in tissue kinetics. Br. J. Cancer 26, 239-257.

Kim, T.S., Benfield, D.A., Rowland, R.R., 2002. Porcine reproductive and respiratory syndrome virus-induced cell death exhibits features consistent with a nontypical form of apoptosis. Virus Res. 85, 133-140.

Kim, Y.M., Bergonia, H., Lancaster Jr., J.R., 1995. Nitrogen oxideinduced autoprotection in isolated rat hepatocytes. FEBS Lett. 374, 228-232.

Kim, Y.M., de Vera, M.E., Watkins, S.C., Billiar, T.R., 1997. Nitric oxide protects cultured rat hepatocytes from tumor necrosis factor-alpha-induced apoptosis by inducing heat shock protein 70 expression. J. Biol. Chem. 272, 1402-1411.

Kluck, R.M., Bossy-Wetzel, E., Green, D.R., Newmeyer, D.D., 1997. The release of cytochrome $c$ from mitochondria: a primary site for Bcl-2 regulation of apoptosis. Science 275, 1132-1136.

Korsmeyer, S.J., 1995. Regulators of cell death. Trends Genet. 11, 101-105.

Labarque, G., Van Gucht, S., Nauwynck, H., Van Reeth, K., Pensaert, M., 2003. Apoptosis in the lungs of pigs infected with porcine reproductive and respiratory syndrome virus and associations with the production of apoptogenic cytokines. Vet. Res. 34, 249-260.

Lowe, S.W., Schmitt, E.M., Smith, S.W., Osborne, B.A., Jacks, T., 1993. p53 is required for radiation-induced apoptosis in mouse thymocytes. Nature $362,847-849$.

Majno, G., Joris, I., 1995. Apoptosis, oncosis, and necrosis. An overview of cell death. Am. J. Pathol. 146, 3-15.

Manji, G.A., Friesen, P.D., 2001. Apoptosis in motion. An apical, P35-insensitive caspase mediates programmed cell death in insect cells. J. Biol. Chem. 276, 16704-16710.

Miller, L.C., Laegreid, W.W., Bono, J.L., Chitko-McKown, C.G., Fox, J.M., 2004. Interferon type I response in porcine reproductive and respiratory syndrome virus-infected MARC-145 cells. Arch. Virol., in press.

Miyashita, T., Krajewski, S., Krajewska, M., Wang, H.G., Lin, H.K., Liebermann, D.A., Hoffman, B., Reed, J.C., 1994. Tumor suppressor p53 is a regulator of bcl-2 and bax gene expression in vitro and in vivo. Oncogene 9, 1799-1805.

Nagata, S., 1997. Apoptosis by death factor. Cell 88, 355-365.

Neilan, J.G., Lu, Z., Afonso, C.L., Kutish, G.F., Sussman, M.D., Rock, D.L., 1993. An African swine fever virus gene with similarity to the proto-oncogene bcl-2 and the Epstein-Barr virus gene BHRF1. J. Virol. 67, 4391-4394.
Nicholson, D.W., Ali, A., Thornberry, N.A., Vaillancourt, J.P., Ding, C.K., Gallant, M., Gareau, Y., Griffin, P.R., Labelle, M., Lazebnik, Y.A., 1995. Identification and inhibition of the ICE/CED-3 protease necessary for mammalian apoptosis. Nature 376, 3743.

Oleksiewicz, M.B., Nielsen, J., 1999. Effect of porcine reproductive and respiratory syndrome virus (PRRSV) on alveolar lung macrophage survival and function. Vet. Microbiol. 66, 15-27.

Oltvai, Z.N., Milliman, C.L., Korsmeyer, S.J., 1993. Bcl-2 heterodimerizes in vivo with a conserved homolog, Bax, that accelerates programmed cell death. Cell 74, 609-619.

Plymale, D.R., Comardelle, A.M., Fermi, C.D., Martin, D.S., Costin, J.M., Norris, C.H., Tencza, S.B., Mietzner, T.A., Montelaro, R.C., Garry, R.F., 1999. Concentration-dependent differential induction of necrosis or apoptosis by HIV-1 lytic peptide 1. Peptides 20, 1275-1283.

Proskuryakov, S.Y., Gabai, V.L., Konoplyannikov, A.G., 2002. Necrosis is an active and controlled form of programmed cell death. Biochemistry (Mosc) 67, 387-408.

Proskuryakov, S.Y., Konoplyannikov, A.G., Gabai, V.L., 2003. Necrosis: a specific form of programmed cell death? Exp. Cell Res. 283, 1-16.

Rasilainen, S., Ylipaasto, P., Roivainen, M., Lapatto, R., Hovi, T., Otonkoski, T., 2004. Mechanisms of coxsackievirus B5 mediated beta-cell death depend on the multiplicity of infection. J. Med. Virol. 72, 586-596.

Ravagnan, L., Gurbuxani, S., Susin, S.A., Maisse, C., Daugas, E., Zamzami, N., Mak, T., Jaattela, M., Penninger, J.M., Garrido, C., Kroemer, G., 2001. Heat-shock protein 70 antagonizes apoptosis-inducing factor. Nat. Cell Biol. 3, 839-843.

Reed, J.C., 1994. Bcl-2 and the regulation of programmed cell death. J. Cell Biol. 124, 1-6.

Revilla, Y., Cebrian, A., Baixeras, E., Martinez, C., Vinuela, E., Salas, M.L., 1997. Inhibition of apoptosis by the African swine fever virus Bcl-2 homologue: role of the BH1 domain. Virology 228, 400-404.

Roy, S., Nicholson, D.W., 2000. Cross-talk in cell death signaling. J. Exp. Med. 192, F21-F26.

Schwartz, L.M., Smith, S.W., Jones, M.E., Osborne, B.A., 1993. Do all programmed cell deaths occur via apoptosis? Proc. Natl. Acad. Sci. U.S.A. 90, 980-984.

Sedlak, T.W., Oltvai, Z.N., Yang, E., Wang, K., Boise, L.H., Thompson, C.B., Korsmeyer, S.J., 1995. Multiple Bcl-2 family members demonstrate selective dimerizations with Bax. Proc. Natl. Acad. Sci. U.S.A. 92, 7834-7838.

Shimizu, S., Eguchi, Y., Kamiike, W., Itoh, Y., Hasegawa, J., Yamabe, K., Otsuki, Y., Matsuda, H., Tsujimoto, Y., 1996. Induction of apoptosis as well as necrosis by hypoxia and predominant prevention of apoptosis by $\mathrm{Bcl}-2$ and $\mathrm{Bcl}-\mathrm{XL}$. Cancer Res. 56, 2161-2166.

Sirinarumitr, T., Zhang, Y., Kluge, J.P., Halbur, P.G., Paul, P.S., 1998. A pneumo-virulent United States isolate of porcine reproductive and respiratory syndrome virus induces apoptosis in bystander cells both in vitro and in vivo. J. Gen. Virol. 79, 29892995.

Suarez, P., Diaz-Guerra, M., Prieto, C., Esteban, M., Castro, J.M., Nieto, A., Ortin, J., 1996. Open reading frame 5 of porcine 
reproductive and respiratory syndrome virus as a cause of virusinduced apoptosis. J. Virol. 70, 2876-2882.

Sur, J.H., Doster, A.R., Christian, J.S., Galeota, J.A., Wills, R.W., Zimmerman, J.J., Osorio, F.A., 1997. Porcine reproductive and respiratory syndrome virus replicates in testicular germ cells, alters spermatogenesis, and induces germ cell death by apoptosis. J. Virol. 71, 9170-9179.

Sur, J.H., Doster, A.R., Osorio, F.A., 1998. Apoptosis induced in vivo during acute infection by porcine reproductive and respiratory syndrome virus. Vet. Pathol. 35, 506-514.

Syntichaki, P., Tavernarakis, N., 2002. Death by necrosis. Uncontrollable catastrophe, or is there order behind the chaos? EMBO Rep. 3, 604-609.

Tan, S.L., Katze, M.G., 1999. The emerging role of the interferoninduced PKR protein kinase as an apoptotic effector: a new face of death? J. Interferon Cytok. Res. 19, 543-554.

Tanaka, N., Sato, M., Lamphier, M.S., Nozawa, H., Oda, E., Noguchi, S., Schreiber, R.D., Tsujimoto, Y., Taniguchi, T., 1998. Type I interferons are essential mediators of apoptotic death in virally infected cells. Genes Cells 3, 29-37.

Thornberry, N.A., Lazebnik, Y., 1998. Caspases: enemies within. Science 281, 1312-1316.

van Lookeren Campagne, M., Lucassen, P.J., Vermeulen, J.P., Balazs, R., 1995. NMDA and kainate induce internucleosomal
DNA cleavage associated with both apoptotic and necrotic cell death in the neonatal rat brain. Eur. J. Neurosci. 7, 16271640.

Waterhouse, N.J., Ricci, J.E., Green, D.R., 2002. And all of a sudden it's over: mitochondrial outer-membrane permeabilization in apoptosis. Biochimie 84, 113-121.

Wyllie, A.H., Kerr, J.F., Currie, A.R., 1980. Cell death: the significance of apoptosis. Int. Rev. Cytol. 68, 251-306.

Young, L.S., Dawson, C.W., Eliopoulos, A.G., 1997. Viruses and apoptosis. Br. Med. Bull. 53, 509-521.

Zhang, C., Gao, C., Kawauchi, J., Hashimoto, Y., Tsuchida, N., Kitajima, S., 2002. Transcriptional activation of the human stress-inducible transcriptional repressor ATF3 gene promoter by p53. Biochem. Biophys. Res. Commun. 297, 13021310.

Zhou, A., Paranjape, J., Brown, T.L., Nie, H., Naik, S., Dong, B., Chang, A., Trapp, B., Fairchild, R., Colmenares, C., Silverman, R.H., 1997. Interferon action and apoptosis are defective in mice devoid of $2^{\prime}, 5^{\prime}$-oligoadenylate-dependent RNase L. EMBO J. $16,6355-6363$.

Zou, H., Henzel, W.J., Liu, X., Lutschg, A., Wang, X., 1997. Apaf-1, a human protein homologous to C. elegans CED-4, participates in cytochrome $c$-dependent activation of caspase-3. Cell 90, 405-413. 